\title{
Xenophobia quelled in the UK
}

The UK Department of Health (London) has begun to fill a long-standing regulatory gap by announcing measures that will permit the consideration of xenotransplant clinical protocols. A public consultation on preliminary guidelines established that "xenotransplant regulation should have statutory backing," according to Frank Dobson, UK Secretary of State for Health. In accordance, the UK Xenotransplantation Interim Regulatory Authority (UKXIRA; London) will become a permanent board, accepting, reviewing and advising the Minister of Health on applications for xenotransplantation experiments in the clinic.

The risk of transmitting disease from animals to humans, and animal welfare are two of the priorities in the regulatory framework. Pig retroviruses-inherited from generation to generation and currently untreatable-have ranked high on international xenotransplant regulators' list of concerns ever since the announcement that pig retroviruses could grow in human tissue (Nat. Med. 3:282). There has been a concentrated international effort to determine how to proceed safely. Xenotransplantation investigators worldwide have willingly donated tissue samples from patients who have received pig islet transplants or undergone pig liver perfusions to the
Center for Disease Control (CDC; Atlanta, $\mathrm{GA}$ ) for assay development and disease screening. CDC spokesperson Louisa Chapman says, "We are still working to develop [viral] assays. Its quite an interesting process because we have to determine what would render a pig retrovirus threatening."

To discuss the risk posed by retroviruses, the UKXIRA sponsored a workshop (August 7) for researchers and industry representatives from the UK, US, and Germany (as European Union representatives). "Discussions are taking place in the European Commission and we want to be sure everyone is singing from the same hymn sheet, "says Denise Shaw, a representative from the UK Department of Health.

David White, president of the Novartis xenotransplantation subsidiary, Imutran (Cambridge, UK), whose announcement in 1995 about bringing his human decay accelerating factor (hDAF) transgenic pig heart model into the clinic helped kick the regulatory process into gear in the UK, is also addressing these disease risks. "We have collected and are screening over a hundred and sixty samples from people who have come in contact with pig tissue."

Imutran-which reported a survival time of up to 90 days in a pig to primate model at the International Congress on Transplant- ation; July $12-17$ in Montreal welcomes the regulatory guidelines. Corinne Sivill, Imutran chief operating officer calls the publication of the UK xenotransplant procedures "an important step forward." The company expects to complete its retroviral safety studies within the next few months and, barring the disclosure of any significant risks, they will subsequently apply to conduct an extracorporeal pig liver perfusion clinical trial.

Because the threat of pig retroviruses is still ill-defined, the UKXIRA has decided to adapt a "proceed with caution" policy-the minister of health has final say in the matter-and is preparing surveillance procedures for any patients who receive animal tissue. The approach is similar to that in US guidelines that are expected to become law later this year.

According to the new UK regulations, primates are off limits as organ sources and the UK Animal Inspectorate will develop a code of practice with regard to raising source animals. Most transgenic animals are already bred and raised in specific pathogen-free barriers facilities to protect the health and integrity of the herd. It is likely that herds intended for xenotransplant purposes will also undergo extensive disease screening.

Barbara Nasto

\section{New "deCODE bill" restarts controversy}

In late July, the Icelandic government published the second draft of its bill to establish a centralized medical and genetics database to be exploited in gene discovery and drug development. The database will be exploited through the grant of an exclusive license for up to 12 years to single company and, although this is not explicitly stated in the bill, the most likely candidate is the largest of Iceland's biotechnology companies, deCODE Genetics (Reykjavik). The new version of the bill does not, however, satisfy its opponents, principally members of Iceland's research and medical communities. They still question the need for centralizing the database and suggest that the bill encapsulates a level of preseumed consent that is significantly lower than globally accepted norms.

Iceland, whose people are nearly all descendants of a few founders who arrived around a thousand years ago provides a unique opportunity for population genetics studies. Kari Stefansson, deCODE's CEO, believes that the island is also set to be a test-bed for some of the ethical and intellectual property issues that surround the commercialization of new genetic analysis techniques. "The current conflict is interesting." he says. "There are several sides to it and what is happening in Iceland is a microcosm of what is happening elsewhere."

One of the fundamental objections to the bill is that it attempts to redefine the anonymization of data that comes from medical and clinical studies. Article 3 of the bill permits the use of medical information that could be traced to a given patient "through the use of decoding key, not available to the person having the information." The key holder is likely to be Iceland's surgeon-general.

This, says Jon Johannes Jonsson, a medical geneticist from the school of medicine at the University of Iceland, redefines the notion of informed consent. Patient data collected in connection with one disease study might be shown by deCODE's in silico mapping techniques to be relevant to another completely separate disease. "If you find genetic loci strongly associated with a disease, what should you do? In a way, you can't go back to the patient because the data is supposed to be anonymous."

But, he says, the surgeon-general, who has a responsibility for the nation's health, might want to inform individuals that they were at risk of disease. For some treatable conditions, like cancer, it could be that most patients would want that information, says Jonsson. But for others, like presenile dementia, the picture is less clear.

The formation in late August of a new Icelandic company provisionally called UVS has helped crystallize the debate about exclusive access to any central medical database. UVS will focus in the genetics of cancer and, according to one of the company's founders, Bernhard Palsson of the University of California, San Diego, will access data gathered and held by the Icelandic Cancer Society, among other sources. "The bill will not stop us from operating." he says.

Although the Icelandic government has made a commitment to get the bill through parliament by October 20 th, that deadline will be under threat if opposition to the bill gains momentum. Also under threat for the time being could be deCODE's initial public offering, which had been planned for the second half of 1998, although Stefansson could not comment on this matter.

John Hodgson 